ORIGINAL ARTICLE

\title{
Trip characteristics of vehicle crashes involving child passengers
}

\author{
I G Chen, D R Durbin, M R Elliott, M J Kallan, F K Winston
}

Injury Prevention 2005;11:219-224. doi: 10.1136/ip.2004.006767

See end of article for authors' affiliations .....................

Correspondence to: Dr I G Chen, 34th and Civic Center Boulevard, 3535 - Traumalink - 10th floor, The Children's Hospital of Philadelphia, Philadelphia, PA 19104, USA; Cheni@email.chop. edu

Accepted 1 February 2005

\begin{abstract}
Objectives: To describe the trip characteristics of vehicle crashes involving children, and to examine the effect of situational factors on front row seating or inappropriate restraint for young children.

Methods: A cross sectional study was conducted on children $<16$ years in crashes of insured vehicles in 15 US states, with data collected using insurance claims records and a telephone interview. A descriptive analysis of the characteristics of vehicle crashes involving children was performed. Multivariate Poisson regression was used to identify situational factors associated with inappropriate restraint or front row seating.

Results: These data suggest that children were traveling in vehicles involved in crashes that occurred under usual driving circumstances - that is, closer to home $(60 \%)$, on a local road $(56 \%)$, during normal daytime hours $(71 \%)$, within areas with relatively lower posted speed limits $(76 \%)$. Compared with children involved in morning crashes, those in daytime crashes ( $R R=1.65,95 \% \mathrm{Cl} 1.13$ to 2.49 ) or in night-time crashes ( $R R=1.63,95 \% \mathrm{Cl} 1.09$ to 2.67 ) were more likely to be sitting in the front seat. Children involved in night-time crashes were more likely to be inappropriately restrained ( $R R=1.12,95 \% \mathrm{Cl} 1.01$ to 1.22 ) than those in daytime crashes. Children riding with two or more additional passengers were more likely to be inappropriately restrained ( $R R=1.12,95 \% \mathrm{Cl} 1.02$ to 1.27 ) than those with no other passengers. Conclusions: Educational initiatives should aim to increase the perception that parents have about the potential crash risk of everyday trips. Some situational characteristics of trips were associated with inappropriate restraint and front row seating behaviors for young children.
\end{abstract}

M otor vehicle crashes continue to be a leading cause of mortality and morbidity for children. ${ }^{1}$ Much attention has been paid to the reduction in injury risk for children through the establishment of recommendations for appropriate restraint ${ }^{2} 3$ for children under age 9 years and through the recommendation of rear row seating for children under age 13 years. ${ }^{4}$ Several situational factors such as time of day, crash location (urban versus rural), the number of passenger, and driver's restraint use have been identified to affect the seatbelt use of both adult and child passengers, ${ }^{5-11}$ or the use of child safety seats and booster seats for young children. ${ }^{12-15}$ For example, one observational study found that when there were three or more passengers in the vehicle, the use of a booster seat for booster seat eligible children decreased. ${ }^{12}$ Thus, one of the many challenges in the appropriate restraint of children in vehicles is that consistent behavior on the part of both parent/drivers and children is required on every trip. ${ }^{16}$

Parental measures of injury prevention for their children are likely to be a function of their health beliefs. ${ }^{17-19}$ Thus, parental perceptions about the hazard associated with the type of trips they take may play a role in the restraint use and seating behaviors of children. Previous research has suggested that many parents perceive certain types of trips to be safer than others, and thus, may allow changes to the usual pattern of restraint use and seating position for child passengers. For example, as found in one recent qualitative study, "some parents indicated that if they are going on a "short" trip, they might choose to use a seat belt as opposed to the booster seat for their child." ${ }^{13}$

Although existing information describing the characteristics of adult involved crashes ${ }^{20} 21$ is available, little information is known specifically about the characteristics of vehicle crashes with child occupants. By characterizing the types of trips that result in crashes involving children, safety messages can be framed in a meaningful way to which parents and caregivers may be more likely to respond. Therefore, the first aim of this study was to describe characteristics of motor vehicle crashes involving children with respect to various child, driver, crash, and trip characteristics. The second aim was to examine whether the likelihood of children under age 13 years traveling in the front seat of the vehicle (hereinafter, referred to as front row seating) varied by trip characteristics or situational factors. The third aim was to examine whether the likelihood of inappropriate restraint varied by trip characteristics or situational factors for children under age 9 years.

\section{METHODS}

Data were collected as part of the Partners for Child Passenger Safety (PCPS) project. A description of the study methods has been published previously. ${ }^{22}$ PCPS consists of a large scale, child specific crash surveillance system: insurance claims from State Farm Insurance Corporation (Bloomington, Illinois) function as the source of subjects, with telephone survey and on-site crash investigations serving as the primary sources of data. Vehicles qualifying for inclusion were State Farm insured, and involved in a crash with at least one child occupant less than 16 years of age. Only model year 1990 and later vehicles were included in order to focus on current vehicle safety design features (for example, the installment of lap-shoulder belts in rear seats of 1990 and post-1990 cars). Qualifying crashes were limited to those that occurred in 15 states and the District of Columbia.

After policyholders consented to participate in the study, limited data were transferred electronically to researchers at The Children's Hospital of Philadelphia and University of Pennsylvania (CHOP/Penn). Data in this initial transfer included contact information for the insured, the ages and 
Table 1 Distribution of child, driver, crash, and trip characteristics among child passengers under age 16 years in vehicle crashes (unweighted, $n=3939$ )

\begin{tabular}{|c|c|c|}
\hline & Weighted (\%) & Unweighted (n) \\
\hline \multicolumn{3}{|l|}{ Child characteristics } \\
\hline \multicolumn{3}{|l|}{ Age (years) } \\
\hline $0-3$ & 28.5 & 847 \\
\hline $4-8$ & 32.3 & 1241 \\
\hline $9-12$ & 22.9 & 1005 \\
\hline $13-15$ & 16.3 & 842 \\
\hline \multicolumn{3}{|l|}{ Sex } \\
\hline Boy & 49.5 & 1911 \\
\hline Girl & 50.5 & 2028 \\
\hline \multicolumn{3}{|l|}{ Restraint use } \\
\hline Appropriate & 63.8 & 2288 \\
\hline Inappropriate & 32.7 & 1357 \\
\hline Unrestrained & 3.0 & 265 \\
\hline Unknown & 0.4 & 29 \\
\hline \multicolumn{3}{|l|}{ Seating row } \\
\hline Front & 23.3 & 1223 \\
\hline Rear & 76.7 & 2708 \\
\hline \multicolumn{3}{|l|}{ Driver characteristics } \\
\hline \multicolumn{3}{|l|}{ Age (years) } \\
\hline$\leqslant 19$ & 4.1 & 347 \\
\hline $20-24$ & 4.1 & 189 \\
\hline $25-34$ & 36.1 & 1262 \\
\hline $35-44$ & 40.1 & 1520 \\
\hline \multirow{2}{*}{\multicolumn{3}{|c|}{ Relation to child }} \\
\hline & & \\
\hline Father & 22.0 & 751 \\
\hline Mother & 56.2 & 2076 \\
\hline Non-parent & 6.7 & 323 \\
\hline Unknown & 15.2 & 789 \\
\hline \multicolumn{3}{|l|}{ Familiarity with trip route } \\
\hline Yes & 95.5 & 2336 \\
\hline No & 4.4 & 123 \\
\hline \multicolumn{3}{|l|}{ In vehicle usually driven } \\
\hline Yes & 87.1 & 3490 \\
\hline No & 12.7 & 444 \\
\hline Unknown & 0.2 & 5 \\
\hline Crash characteristics & & \\
\hline Near an intersection & & \\
\hline Yes & 49.0 & 2035 \\
\hline No & 50.7 & 1894 \\
\hline Unknown & 0.3 & 10 \\
\hline Vehicle type & & \\
\hline Passenger cars & 46.5 & 2099 \\
\hline Large vans & 4.2 & 134 \\
\hline Pick up trucks & 6.6 & 227 \\
\hline SUVs & 16.5 & 581 \\
\hline Passenger vans & 26.2 & 898 \\
\hline Collision type & & \\
\hline Another vehicle & 81.1 & 3173 \\
\hline Object & 17.1 & 650 \\
\hline Other & 14.0 & 106 \\
\hline Crash time & & \\
\hline Morning (6:00am-9:59am) & 12.6 & 567 \\
\hline Daytime (10:00am-6:59 pm) & 71.3 & 2673 \\
\hline Night-time (7:00pm-5:59am) & 16.1 & 688 \\
\hline Trip characteristics & & \\
\hline Purpose & & \\
\hline Shopping/running errands & 30.0 & 1088 \\
\hline Transporting & 35.6 & 1481 \\
\hline Recreation & 27.1 & 1057 \\
\hline Other & 7.3 & 313 \\
\hline Minutes from home & & \\
\hline$\leqslant 10$ & 59.5 & 2351 \\
\hline $11-30$ & 30.6 & 1138 \\
\hline $31-60$ & 5.1 & 241 \\
\hline More than 1 hour & 4.8 & 183 \\
\hline Posted speed limit & & \\
\hline$\leqslant 30 \mathrm{mph}$ & 29.8 & 835 \\
\hline $35-45 \mathrm{mph}$ & 46.4 & 1628 \\
\hline$\geqslant 50 \mathrm{mph}$ & 23.8 & 921 \\
\hline Road type & & \\
\hline Divided highway & 20.9 & 889 \\
\hline Non-divided highway & 8.8 & 435 \\
\hline Local road & 56.0 & 2271 \\
\hline Parking lot/other & 14.3 & 329 \\
\hline
\end{tabular}

sex of all child occupants, and a coded variable describing the level of medical treatment received by all child occupants as
Table 1 Continued

\begin{tabular}{|c|c|c|}
\hline & Weighted (\%) & Unweighted (n) \\
\hline \multicolumn{3}{|c|}{ Number of passengers* } \\
\hline 1 child & 27.1 & 1072 \\
\hline 2 & 34.7 & 1347 \\
\hline$\geqslant 3$ & 38.1 & 1520 \\
\hline Total & 100 & 3939 \\
\hline \multicolumn{3}{|c|}{$\begin{array}{l}\text { Note: due to missing data, the total unweighted number for each } \\
\text { characteristic may not add up to } 3939 \text {. } \\
\text { *Each category includes at least one child passenger. }\end{array}$} \\
\hline
\end{tabular}

reported by the policyholder (no treatment, physician's office or emergency department only, admitted to the hospital, or death).

A stratified cluster sample was designed in order to select vehicles (the unit of sampling) for the conduct of a telephone survey with the driver. In the first stage of sampling, vehicles were stratified on the basis of whether they were towed from the scene or not, and a probability sample of both towed and non-towed vehicles was selected at random, with a higher probability of selection for towed vehicles. In the second stage of sampling, vehicles were stratified on the basis of the level of medical treatment received by child occupant(s). The probabilities of selection ranged from 0.025 for vehicles in which no child received medical treatment to 1.0 for vehicles in which a child died or was admitted to the hospital. If a vehicle were sampled, the "cluster" of all child occupants in that vehicle was included in the survey.

Drivers of sampled vehicles were contacted by phone and screened via an abbreviated survey to verify the presence of at least one child occupant with an injury. The full interview involved a 30 minute telephone survey with the driver of the vehicle and parent(s) of the involved children. Only parents and drivers 16 years of age or older were interviewed. The study protocol was reviewed and approved by the Institutional Review Boards of both CHOP/Penn.

The study population consisted of 430308 children riding in 288187 vehicles reporting a crash claim between 1 December 1998 and 30 November 2002. Comparing the included sample with known population values from State Farm claims, we see little difference in the vehicle type, the drivable status of the vehicle, and the mean age of the child occupants. The cross sectional analyses below are restricted to the complete interviews on 3939 children conducted between 1 March 2000 and 28 February 2001, during which time the trip characteristics questions were asked.

\section{Variables definition}

Three levels of restraint use were defined: appropriate restraint, inappropriate restraint, and no restraint. Appropriate restraint was defined as restrained children: under age 1 year who were in a rear facing child safety seat; aged 1-3 years who were in a child safety seat; aged 4-8 years who were restrained in any child restraint (mostly belt positioning booster seat), as adapted from AAP and NHTSA recommendations, ${ }^{2}{ }^{3}$ and as both lap and shoulder belt use for 9-15 year olds. Inappropriate restraint was defined as children aged less than 1 year in a forward facing child safety seat, any seat belt use for children aged 1-8 years, or a lap belt or shoulder belt only for children aged 9-15 years.

Crash characteristics included whether or not the crash occurred near an intersection (at or approaching an intersection), the vehicle type (passenger car, pickup truck, large van, sport utility vehicle), the type of collision (with another vehicle versus with an object), and crash time (morning, 6:00 am-9:59 am; daytime, 10:00 am-6:59 pm; night-time, 7:00 pm-5:59 am). 
Table 2 Percentage of front row seating by trip characteristics among child passengers under age 13 years who were the only passenger in the vehicle (unweighted, $\mathrm{n}=739$ )

\begin{tabular}{|c|c|c|c|}
\hline & $\begin{array}{l}\text { Unweighted, } \\
\text { n (weighted, \%) }\end{array}$ & $\begin{array}{l}\text { Weighted \% } \\
\text { for front row } \\
\text { seating } \\
\text { (unweighted, n) }\end{array}$ & p Value \\
\hline Child's age (years) & & & $<0.001$ \\
\hline$\leqslant 3$ & $229(39.8)$ & $4.2(19)$ & \\
\hline $4-8$ & 269 (33.3) & 32.7 (132) & \\
\hline $9-12$ & $241(26.9)$ & $75.8(201)$ & \\
\hline Driver's age (years) & & & 0.03 \\
\hline$\leqslant 25$ & $102(11.3)$ & $20.2(39)$ & \\
\hline$>25$ & 637 (88.7) & 34.6 (313) & \\
\hline Crash time & & & 0.04 \\
\hline $\begin{array}{l}\text { Morning } \\
\text { (6:00am-9:59am) }\end{array}$ & $150(19.1)$ & $20.7(59)$ & \\
\hline $\begin{array}{l}\text { Daytime } \\
\text { (10:00am-6:59pm) }\end{array}$ & $486(68.8)$ & 34.7 (235) & \\
\hline $\begin{array}{l}\text { Night-time } \\
\text { (7:00pm-5:59am) }\end{array}$ & $100(12.1)$ & $40.0(55)$ & \\
\hline Trip purpose & & & $<0.001$ \\
\hline Recreational & $139(18.1)$ & $52.2(83)$ & \\
\hline Non-recreational & 600 (81.2) & $28.8(269)$ & \\
\hline Overall & & $33.0(352)$ & \\
\hline
\end{tabular}

Note: due to missing data, the total unweighted number for each characteristic may not add up to 739 .

Among the trip characteristics, trip purpose included shopping/running errands, transporting child or going to/ from (the driver's) work, recreational trips, and other types of trips. These categories were further collapsed as recreational and non-recreational trips. Distance from home was determined by the driver's estimate of the driving time from the crash location to driver's home ( $\leqslant 10$ minutes, $11-30$ minutes, 31-60 minutes, and more than 1 hour). Posted speed limit was categorized as $30 \mathrm{mph}$ and lower, 35-45 $\mathrm{mph}$, and $50 \mathrm{mph}$ and more. Road type was defined as divided highway, non-divided highway, local road, parking lot, and other.

\section{Data analysis}

The analyses for the first aim described the various characteristics of motor vehicle crashes involving child occupants using frequency distributions for categorical variables. The analyses for the second aim determined the proportion of children in the front row by trip characteristics among children under age 13 years. As a child's seating position (front $v$ rear) was highly affected by the number of passengers in the vehicle, the analyses were restricted to children who were the only passenger in the vehicle. The analyses for the third aim were to compare the distribution of the restraint status among young children by trip characteristics. These analyses were limited to children under age 9 years because most educational campaigns emphasize age appropriate restraint use for children under this age. Pearson $\chi^{2}$ tests were performed to assess the statistical significance of the observed differences. For the univariate and bivariate analyses, SAS callable SUDAAN ${ }^{23}$ was used to account for sampling weights, sampling strata, and sampling units.

For the multivariate analyses, we computed adjusted relative risks (RRs) using Poisson regression with a log link. To account for the fact that the regression residuals do not have a Poisson distribution due to the dichotomous nature of the outcomes of interest, a bootstrap procedure was used to compute $95 \%$ confidence intervals (CIs) for the Poisson regression parameters of interest. This procedure also accounted for the use of the sampling weights.
Table 3 Multivariate Poisson regression analysis of front row seating for children under age 13 years who were the only passenger in the vehicle (unweighted, $n=739$ )

\begin{tabular}{|c|c|c|}
\hline \multirow[b]{2}{*}{ Correlates } & \multicolumn{2}{|l|}{ Front row seating } \\
\hline & $\operatorname{RR}(95 \% \mathrm{Cl})$ & p Value \\
\hline \multicolumn{3}{|l|}{ Child's age (years) } \\
\hline$\leqslant 3$ & $1.00(-)$ & \\
\hline $4-8$ & $7.80(4.12-25.57)$ & $<0.001$ \\
\hline $9-12$ & $17.31(10.25-56.42)$ & $<0.001$ \\
\hline \multicolumn{3}{|l|}{ Driver's age (years) } \\
\hline$\leqslant 25$ & $1.00(-)$ & \\
\hline$>25$ & $0.86(0.54-1.56)$ & 0.57 \\
\hline \multicolumn{3}{|l|}{ Crash time } \\
\hline Morning (6:00am-9:59am) & $1.00(-)$ & \\
\hline Daytime (10:00am-6:59pm) & $1.65(1.13-2.49)$ & 0.01 \\
\hline Night-time (7:00pm-5:59am) & $1.63(1.09-2.67)$ & 0.04 \\
\hline \multicolumn{3}{|l|}{ Trip purpose } \\
\hline Non-recreational & $1.00(-)$ & \\
\hline Recreational & $1.24(0.93-1.60)$ & 0.11 \\
\hline
\end{tabular}

\section{RESULTS}

\section{Results for aim 1}

Completed interviews were obtained on 3939 children in 2462 crashes representing 67981 children in 43080 crashes. In table 1 , the majority of the children were riding with drivers familiar with the route $(95 \%)$, and in vehicles that drivers typically used (87\%). Overall, half $(49 \%)$ of the children were riding in vehicles involved in crashes occurring near an intersection. Most of the children were traveling in vehicles involved in crashes with another vehicle $(81 \%)$. About $71 \%$ of the children were traveling in vehicles involved in daytime crashes; $13 \%$ in morning crashes; $16 \%$ in nighttime crashes.

The distribution of trip purposes was: $30 \%$ of children were for shopping/running errands, $36 \%$ were for child transportation or going to/from (the driver's) work, $27 \%$ were on recreational trips, and $7 \%$ were on other types of trips. Over half of the children were in crashes $\leqslant 10$ minutes driving time from the driver's home, with only $5 \%$ of them at a crash location with one hour or more from home. Three quarters of the children were riding in vehicles involved in crashes on roads where the posted speed limit was $45 \mathrm{mph}$ or lower. Over half of the children were in crashes on local roads; $21 \%$ on divided highways; less than $10 \%$ on non-divided highways; approximately $14 \%$ in parking lots or other locations.

\section{Results for aim 2}

During the study period, 739 children under age 13 years were identified as the only passenger in the vehicle, representing 13950 children. Overall, 33\% of children were sitting in the front row at the time of crash (table 2). Older children $(p<0.001)$, children with drivers over 25 years of age $(p=0.03)$, children being driven at night-time or daytime $(p=0.04)$ and children on recreational trips $(p<0.001)$ were all more likely to be front row seated. Driver's sex $(p=0.34)$, posted speed limit $(p=0.62)$, distance from home $(p=0.50)$, and road type $(p=0.94)$ were not associated with child's front row seating.

The results of multivariate analyses demonstrated that after controlling for both child and driver age, trip purpose, and time of the crash, only child age and the crash time were significantly associated with a child's front row seating (table 3). Compared with children under age 4 years, older children ( $4-8$ years: $\mathrm{RR}=7.80,95 \%$ CI 4.12 to 25.57 ; 9-12 years: $R R=17.31,95 \%$ CI 10.25 to 56.42 ) were more likely to sit in the front seat. Concurrently, compared with children in morning crashes, children in daytime crashes 
Table 4 Distribution of restraint status by trip characteristics among children under age 9 years (unweighted, $n=2088$ )

\begin{tabular}{|c|c|c|c|c|c|}
\hline & $\begin{array}{l}\text { Unweighted, } \\
\text { n (weighted, } \\
\% \text { ) }\end{array}$ & $\begin{array}{l}\text { Appropriate } \\
\text { restraint } \\
\text { (unweighted, } \\
\mathrm{n}=883 \text { ) } \\
\text { weighted, \% } \\
\text { (unweighted, n) }\end{array}$ & $\begin{array}{l}\text { Inappropriate } \\
\text { restraint } \\
\text { (unweighed, } \\
\mathrm{n}=1117 \text { ) } \\
\text { weighted, \% } \\
\text { (unweighted, n) }\end{array}$ & $\begin{array}{l}\text { No restraint } \\
\text { (unweighted, } \\
\mathrm{n}=79 \text { ) } \\
\text { weighted, \% } \\
\text { (unweighted, n) }\end{array}$ & p Value \\
\hline Child's age (years) & & & & & $<0.001$ \\
\hline$<1$ & 204 (12.2) & 77.5 (142) & $22.5(61)$ & $0.02(1)$ & \\
\hline $1-3$ & $643(34.8)$ & $93.8(587)$ & $5.4(49)$ & $0.9(6)$ & \\
\hline $4-8$ & $1241(53.1)$ & $17.9(154)$ & $78.6(1007)$ & $3.6(72)$ & \\
\hline Driver's age (years) & & & & & 0.14 \\
\hline$\leqslant 25$ & $263(10.9)$ & $59.4(131)$ & $39.6(124)$ & $1.1(8)$ & \\
\hline$>25$ & $1821(89.1)$ & $50.5(749)$ & $47.1(992)$ & $2.4(71)$ & \\
\hline Crash time & & & & & 0.15 \\
\hline Morning (6:00am-9:59am) & $321(13.7)$ & 50.9 (139) & $47.3(165)$ & $1.8(16)$ & \\
\hline Daytime (10:00am-6:59pm) & $1454(71.5)$ & 53.7 (634) & $44.0(760)$ & $2.3(52)$ & \\
\hline Night-time (7:00pm-5:59am) & 310 (14.8) & $42.5(109)$ & 55.4 (190) & $2.1(11)$ & \\
\hline Trip purpose & & & & & 0.19 \\
\hline Shopping/errands & $623(32.0)$ & $52.1(275)$ & $45.8(323)$ & $2.1(21)$ & \\
\hline Transporting & $841(38.6)$ & $55.3(371)$ & $43.3(439)$ & $1.5(30)$ & \\
\hline Recreation & $454(22.0)$ & $43.7(167)$ & $53.0(267)$ & $3.3(18)$ & \\
\hline Other & $170(7.4)$ & $53.2(70)$ & 43.5 (88) & $3.3(10)$ & \\
\hline Trip purpose & & & & & 0.03 \\
\hline Recreational & $454(22.0)$ & $43.7(167)$ & $53.0(267)$ & $3.3(18)$ & \\
\hline Non-recreational & $1634(78.0)$ & $53.8(716)$ & $44.3(850)$ & $1.9(61)$ & \\
\hline Number of passengers & & & & & $<0.001$ \\
\hline 1 & $514(25.7)$ & $59.0(247)$ & $40.5(254)$ & $0.5(13)$ & \\
\hline 2 & $763(36.2)$ & $54.0(333)$ & $43.4(397)$ & $2.6(31)$ & \\
\hline$\geqslant 3$ & $811(38.1)$ & $44.2(303)$ & $52.8(466)$ & $3.0(35)$ & \\
\hline
\end{tabular}

$(\mathrm{RR}=1.6595 \% \mathrm{CI} 1.13$ to $2.49, \mathrm{p}=0.01)$ or in night-time crashes ( $R R=1.63,95 \%$ CI 1.09 to $2.67, p=0.04)$ were more likely to be front row seated.

\section{Results for aim 3}

This set of analyses was restricted to the 2088 children under age 9 years in 1475 crashes, representing 41318 children in 28885 crashes. About $2 \%$ of the children were unrestrained; $46 \%$ were inappropriately restrained. More children were inappropriately restrained on a recreational trip $(53.0 \%)$ than those on a non-recreational trip $(\mathrm{p}=0.03)$ (table 4). When the child was alone in the vehicle with the driver, $40 \%$ of the children were inappropriately restrained. However, when the number of additional passengers was three or more, more

Table 5 Multivariate Poisson regression analysis of inappropriate restraint for restrained children under age 9 years (unweighted, $n=2009$ )

\begin{tabular}{|c|c|c|}
\hline \multirow[b]{2}{*}{ Correlates } & \multicolumn{2}{|c|}{ Inappropriate restraint } \\
\hline & $\operatorname{RR}(95 \% \mathrm{CI})$ & p Value \\
\hline \multicolumn{3}{|l|}{ Child's age (years) } \\
\hline$<1$ & $1.00(-)$ & \\
\hline $1-3$ & $0.24(0.14-0.41)$ & $<0.001$ \\
\hline $4-8$ & $3.62(2.76-5.37)$ & $<0.001$ \\
\hline \multicolumn{3}{|l|}{ Driver's age (years) } \\
\hline$\leqslant 25$ & $1.00(-)$ & \\
\hline$>25$ & $0.84(0.73-0.95)$ & 0.01 \\
\hline \multicolumn{3}{|l|}{ Crash time } \\
\hline Morning \& daytime (6:00am-6:59pm) & $1.00(-)$ & \\
\hline Night-time (7:00pm-5:59am) & $1.12(1.01-1.22)$ & 0.02 \\
\hline \multicolumn{3}{|l|}{ Trip purpose } \\
\hline Non-recreational & $1.00(-)$ & \\
\hline Recreational & $1.03(0.94-1.13)$ & 0.53 \\
\hline \multicolumn{3}{|l|}{ Number of passengers* } \\
\hline One child & $1.00(-)$ & \\
\hline 2 & $1.03(0.93-1.17)$ & 0.59 \\
\hline$\geqslant 3$ & $1.12(1.02-1.27)$ & 0.04 \\
\hline
\end{tabular}

than half $(53 \%)$ of them were inappropriately restrained or unrestrained $(p<0.001)$. The driver's sex $(p=0.67)$, posted speed limit $(p=0.97)$, distance from home $(p=0.82)$, and road type $(p=0.74)$ were not associated with the child's restraint status.

The multivariate analyses for inappropriate restraint use were conducted on restrained children (table 5). Compared to children younger than 1 year, those aged $1-3$ years were less likely to be inappropriately restrained ( $R R=0.24,95 \% \mathrm{CI}$ 0.14 to $0.41, \mathrm{p}<0.001$ ) while those aged $4-8$ years were more likely to be inappropriately restrained ( $R R=3.62,95 \% \mathrm{CI}$ 2.76 to $5.37, \mathrm{p}<0.001)$. Children riding with drivers aged 26 years and older were more likely to be appropriately restrained than children riding with drivers aged 25 years and younger $(\mathrm{RR}=0.84,95 \% \mathrm{CI} 0.73$ to $0.95, \mathrm{p}=0.02$ ). Children traveling in vehicles involved in night-time crashes were more likely to be inappropriately restrained $(R R=1.12$, $95 \%$ CI 1.01 to $1.22, p=0.02$ ) than those in other crashes. Children riding with two or more additional passengers were more likely to be inappropriately restrained $(\mathrm{RR}=1.12,95 \%$ CI 1.02 to $1.27, \mathrm{p}=0.04)$ than those with no other passengers.

\section{DISCUSSION}

In this study we describe the characteristics of trips that resulted in motor vehicle crashes involving children. Most children were in crashes occurring close to home, on local roads, on routes familiar to the driver, and within areas with relatively low speed limits. In addition, crashes occurred on trips describing the full range of activities for which parents commonly transport children and typically occurred during daytime hours, which corresponds to there being more daytime activities to which children need to be transported. These data suggest that children were traveling in vehicles involved in crashes occurring under usual driving circumstances rather than unusual circumstances. Educational initiatives should aim to increase the perception that parents have about the potential crash risk of everyday trips. 
One qualitative study ${ }^{12}$ suggests the number of passengers may affect a child's restraint use while one quantitative study ${ }^{9}$ demonstrates that the number of passengers was significantly associated with a child's seat belt use. Our study confirms that increasing the number of passengers reduces the likelihood that a child under 9 years will be appropriately restrained. It is possible that as the number of occupants in the vehicle increase, there may be less availability of restraints or adequate space in which to install a child safety seat or booster seat. Whenever possible, parents must avoid transporting more children than can be restrained appropriately. As noted earlier, parents report that they may not pay as strict attention to the restraint needs of their children on short trips. ${ }^{12}$ However, we found no association between distance from home and restraint status, similar to a recent study which reported that distance driven did not predict booster seat use by child passengers. ${ }^{14}$

Time of day is an important factor associated with a driver's behaviour. ${ }^{24}$ Several studies ${ }^{78}$ also found that time of day (day versus night) is a predictor of seat belt use for drivers or their passengers. Our findings of more inappropriate restraint use by young children in night-time crashes, and more young children riding in the front seat in daytime or night-time crashes are similar to these previous reports.

According to recent findings from qualitative research, ${ }^{15}$ one of the reasons for parent's non-use of booster seat for their children is because parents do not understand the importance of appropriate restraint for children on every trip. Thus, appealing to their sense of risk, by clarifying that most crashes involving children occur during usual driving circumstances, may be an effective way of improving appropriate restraint of children. Furthermore, although the age appropriate restraint use can effectively reduce injury risk for young children, ${ }^{25} 26$ the misuse of appropriate restraints such as misrouting vehicle safety belt through child safety seat, may compromise the effectiveness of the restraint system. Several studies have reported high prevalence of misuse of child safety seats. ${ }^{27-29}$ Thus, it is also important for parents/drivers to correctly use child safety seats or booster seats for young children on every trip.

Currently, many states are upgrading their child restraint laws to include provisions for the use of age appropriate restraints through ages 6-8 years, enabling the law to be in closer alignment with best practice recommendations. At the time of this paper's writing, 28 states and the District of Columbia have recently included provisions for the use of age appropriate restraints for children over 4 years of age. ${ }^{30}$ However, fewer than 10 states have also included a provision requiring rear seating for children. The National Transportation Safety Board recommends that all states enact legislation to require the transport of children age 12 years and under in a rear seat of a passenger vehicle if a rear seating position is available. ${ }^{31}$ In addition, more comprehensive child restraint laws, and the primary enforcement of those laws, may increase appropriate restraint use and rear seating for young children, even in situations where parents do not perceive their child to be at risk. In particular, enforcement should be increased during the night-time.

There are several limitations to this study. The use of single insurance company data may not be representative of the entire insured population. However, given the large market share of State Farm in the study regions, there is no reason to suspect that its population differs substantially from the overall insured population in these regions. This study relied on driver report (mostly parents) for information on restraint types and seating position of children, and may be subject to recall bias. Also, due to the effect of social desirability, drivers might underreport inappropriate child restraint use and front row seating for younger child passengers. However, our

\section{Key points}

- Children were traveling in vehicles involved in crashes occurring under usual driving circumstances rather than unusual circumstances.

- Educational initiatives should aim to increase the perception that parents have about the potential crash risk of everyday trips.

- Some situational characteristics of the trips were associated with inappropriate restraint and front row seating behaviors for young children.

- Given the potential crash risk of everyday trips, it is very important to follow recommendations for optimal safety for children in vehicles on every trip.

results on age specific restraint use and seating position are similar to those of other recently reported population based studies of young child occupants. ${ }^{32}{ }^{33}$ Another limitation is that we did not use child's weight and height as the basis for determining appropriate/inappropriate restraint use. Yet, this age based definition reflects the recent trend of many more children stayed in child safety seats through ages 4 and 5 years. $^{34}$

\section{CONCLUSION}

Children were involved in vehicle crashes that occur under circumstances that likely describe the common trips that children take in cars. Educational efforts should direct at increasing the parents' or drivers' crash risk perception about daily trips in vehicles. Some situational characteristics of trips were associated with inappropriate restraint and front row seating behaviors for young children. Therefore, given the potential crash risk of everyday trips, it is important to follow recommendations for optimal safety for children in vehicles on every trip. Further research is needed to understand the determinants of these situational unsafe behaviors in order to design more effective interventions to influence them.

\section{ACKNOWLEDGEMENTS}

The authors would like to thank State Farm for their financial support of this work through the Partners for Child Passenger Safety project, as well as many dedicated claim representatives and personnel from State Farm, and the parents who generously agreed to participate in the study. The authors would also like to thank Rebecca Cornejo, MHS for her contributions to an earlier version of this work and the anonymous reviewers for their very useful comments.

\section{Authors' affiliations}

I G Chen, F K Winston, D R Durbin, The Department of Pediatrics, The Children's Hospital of Philadelphia, Philadelphia, PA, USA

D R Durbin, M R Elliott, M J Kallan, The Center for Clinical Epidemiology and Biostatistics, University of Pennsylvania School of Medicine, PA, USA

\section{REFERENCE}

1 Committee on Injury Prevention and Control. Reducing the burden of injury: advancing prevention and treatment, In: FC, Bonnie R, Liverman C, eds. Washington DC: National Academy Press, 1999

2 American Academy of Pediatrics. Selecting and using the most appropriate car safety seats for growing children: guidelines for counseling parents. Pediatrics 2002;109:550-3.

3 National Highway Traffic Safety Administration. Child passenger safety. Available at http://www.nhtsa.dot.gov/people/injury/childps (accessed 1 February 2003).

4 National Transportation Safety Board. Recommendations on airbags, safety belts, and child restraints. NTSB: Washington, DC 1997.

5 Fockler SK, Cooper PJ. Situational characteristics of safety belt use. Accid Anal Prev 1990;22:109-18. 
6 Li L, Kim K, Nitz L. Predictors of safety belt use among crash-involved drivers and front seat passengers: adjusting for over-reporting. Accid Anal Prev 1999;31:631-8.

7 Baker DR, Clarke SR, Brandt EN Jr. An analysis of factors associated with seat belt use: prevention opportunities for the medical community. J Okla State Med Assoc 2000;93:496-500.

$8 \mathrm{Kim}$ S, Kim K. Personal, temporal and spatial characteristics of seriously injured crash-involved seat belt non-users in Hawaii. Accid Anal Prev 2003;35:121-30

9 Edgerton EA, et al. Predictors of seat-belt use among school-aged children in two low-income Hispanic communities. Am J Prev Med 2002;22:113-16.

10 McCartt AT, Northrup VS. Factors related to seat belt use among fatally injured teenage drivers. J Safety Res 2004;35:29-38.

11 Maron DJ, et al. Correlates of seat-belt use by adolescents: implications for health promotion. Prev Med 1986;15:614-23.

12 Ramsey A, Simpson E, Rivara FP. Booster seat use and reasons for nonuse. Pediatrics 2000; 106:E20.

13 Simpson EM, Moll EK, Kassam-Adams N, et al. Barriers to booster seat use and strategies to increase their use. Pediatrics 2002;110:729-36.

14 National Highway Traffic Safety Administration. National Occupant Protection Use Survey, 2002

15 Ebel BE, et al. Too small for a seatbelt: predictors of booster seat use by child passengers. Pediatrics 2003;111:e323-7.

16 National Highway Safety Administration. Best practices for promoting booster seat use. Available at http://www.nhtsa.dot.gov/CPS/promote/ learn.htm\#insights (accessed 8 March 2005).

17 Peterson L, Farmer J, Kashani JH. Parental injury prevention endeavors: a function of health beliefs? Health Psychol 1990;9:177-91.

18 Morrongiello BA, Dayler L. A community-based study of parents' knowledge, attitudes and beliefs related to childhood injuries. Can J Public Health 1996;87:383-8

19 Mulligan-Smith D, Puranik S, Coffman S. Parental perception of injury prevention practices in a multicultural metropolitan area. Pediatr Emerg Care 1998;14:10-14.

20 National Highway Traffic Safety Administration. Traffic Safety Facts 2000. Available at http://www-nrd.nhtsa.dot.gov/pdf/nrd-30/NCSA/TSFAnn/ TSF2000.pdf (accessed 12 May 2004).
21 Retting RA, Ulmer RG, Williams AF. Prevalence and characteristics of red light running crashes in the United States. Accid Anal Prev 1999;31:687-94.

22 Durbin DR, et al. Partners for Child Passenger Safety: a unique child-specific crash surveillance system. Accid Anal Prev 2001;33:407-12.

23 SUDAAN, Software for the Statistical Analysis of Correlated Data. Research Triangle Park, NC: Research Triangle Institute, 2001.

24 Parker $\mathbf{D}$, et al. Determinants of intention to commit driving violations. Accid Anal Prev 1992;24:117-31.

25 Arbogast KB, et al. An evaluation of the effectiveness of forward facing child restraint systems. Accid Anal Prev 2004;36:585-9.

26 Durbin DR, Elliott MR, Winston FK. Belt-positioning booster seats and reduction in risk of injury among children in vehicle crashes. JAMA 2003;289:2835-40

27 Eby DW, Kostyniuk LP. A statewide analysis of child safety seat use and misuse in Michigan. Accid Anal Prev 1999;31:555-66.

28 Decina LE, Knoebel KY. Child safety seat misuse patterns in four states. Accid Anal Prev 1997;29:125-32.

29 Campbell H, Macdonald S, Richardson P. High levels of incorrect use of car seat belts and child restraints in Fife-an important and under-recognised road safety issue. Inj Prev 1997;3:17-22.

30 Insurance Institute for Highway Safety. Table of Child Restraint Laws. Available at http://www.hwysafety.org/safety\%5Ffacts/state\%5Flaws/ restrain2.htm (accessed 20 September 2004).

31 National Transportation Safety Board. The State of Child Passenger Safety in America, Remarks by Jim Hall, Chairman of NTSA at the Lifesavers 2000 Conference on March 13, 2000. Available at http://www.ntsb.gove/speeches/ihc000313.htm /accessed 20 September 2004).

32 Glassbrenner D. The use of child restraints in 2002. National Highway Traffic Safety Administration, 2003.

33 Kindelberger J, Starnes M. Moving children from the front seat to the back seat: the influence of child safety campaigns. National Highway Traffic Safety Administration, 2003

34 Winston FK, et al. Recent trends in child restraint practices in the United States. Pediatrics 2004;113:e458-64.

\section{COCHRANE CORNER}

\section{Cochrane Library feedback}

O ne of the potentially most useful features of the Cochrane Library is the "Add/View Feedback" link positioned (alas, not very conspicuously) towards the bottom of the menu that appears each time a review (or a protocol for a review) is selected. Users of the Library can leave their own comments or criticisms and see what others might have said. It is possible, for example, to query the approach that reviewers have described in their protocol or to draw attention to new trials published since a review was last updated. Like other Cochrane review groups, however, we find that this facility is seldom used.

It is interesting when a review bucks the trend and attracts copious feedback. The Cochrane Injuries Group review that has been most successful in prompting readers to post their comments is "Helmets for preventing head and facial injuries in bicyclists", " which concluded, "Helmets reduce bicyclerelated head and facial injuries for bicyclists of all ages involved in all types of crashes, including those involving motor vehicles". The explanation for the interest in this review seems to be that anti-helmet passions are currently running high, as has often been the case with road safety interventions-for example, seatbelts.

Some of the comments posted on the helmet review are longer than the review itself. It is unfortunate that the same points have been made (often by the same people) over and over again, and that most of the criticism has very little to do with the review itself, involving instead discussion of theoretical issues relating to helmet use. Indeed, the critics have argued that only when the theory for an intervention is good should a systematic review be carried out of its use in practice. This is very far from the view taken within the Cochrane Collaboration; if an intervention is in widespread use (and many of us wear cycle helmets) there is a pressing need to evaluate its real world effectiveness. If reviewers had waited till the theory looked good, then many of the drugs in common use would never have been the subject of a systematic review!

The helmet review's critics have also made, and repeated, incorrect statements about individual studies included in the review. So, all in all, this is not an instance of the comments facility being used effectively. Nevertheless, we do hope to get more feedback on our work, including another review and a protocol that also deal with bicycle helmets. ${ }^{23}$

This will be the last time that this column is written by me. I am moving to become an Editor with PloS Medicine, the new open access general medical journal from the Public Library of Science (http://www.plos.org). However, I shall retain my interest in injury prevention, which is a field that we need to see covered more fully and more often in the general medical literature.

P Chinnock Managing Editor, Cochrane Injuries Group; paul.chinnock@|shtm.ac.uk doi: 10.1136/ip.2005.009431

\section{References}

1 Thompson DC, Rivara FP, Thompson R. Helmets for preventing head and facial injuries in bicyclists. The Cochrane Database of Systematic Reviews, 1999, Issue 4. Art No: CD001855, DOI:10.1002/14651858.CD001855.

2 Royal ST, Kendrick D, Coleman T. Non-legislative interventions for the promotion of cycle helmet wearing by children. The Cochrane Database of Systematic Reviews, 2005, Issue 2. Art No: CD003985, DOI:10.1002/ 14651858.CD003985.pub2.

3 Macpherson A, Spinks A. Bicycle helmet legislation for the prevention of head injuries patients (Protocol). The Cochrane Database of Systematic Reviews (in press) 